Gut, 1977, 18, 855-864

\title{
Anatomy and radiology of the areae gastricae
}

\author{
C. E. MACKINTOSH AND L. KREEL
}

From the Radiology Divisions of the Royal Free Hospital and the Clinical Research Centre, Northwick Park Hospital, Middlesex

SUMMARY The anatomy and radiology of the areae gastricae were studied in human and pig specimens and it was shown that the double contrast barium meal demonstrates a true picture of the undulating gastric mucosa, which is distinctive in appearance in the antrum body and fundus of the pig stomach. The importance of the type of barium used and the thickness of barrier mucus in the demonstration of the areae pattern is emphasised and the high incidence of duodenal ulcer in the grade 4 pattern and the low incidence in the non-coater is described. A knowledge of the anatomy and radiology of the areae gastricae pattern is central to the interpretation of the double contrast barium meal.

The anatomy of the areae gastricae can be considered from two points of view-that of the radiologist and of the anatomist. The object of this paper is to combine the information from both disciplines in such a way as to create a meaningful clinical picture of the anatomy of the gastric mucosa for the rational interpretation of the double contrast barium meal.

\section{Radiological appearance}

The pattern of the areae gastricae as seen by the radiologist consists of a mosaic produced by barium lying in the intervening grooves of the gastric mucosa (Fig. 1); the distance between the grooves varies from approximately $1 \mathrm{~mm}$ to $4-5 \mathrm{~mm}$ and the area of gastric mucosa bound by the grooves is the socalled areae gastricae. While this pattern is startlingly evident in a double contrast barium meal using the correct technique, it is to be noted that a groove pattern is seldom clearly visualised at gastroscopy in our experience while using an Olympus GIF 2D panendoscope. In this sense, the double contrast barium meal resolves one aspect of mucosal anatomy more clearly than the endoscope and failure to appreciate this point can lead to confusion between endoscopists and radiologists. We have as yet failed to find a suitable dye to spray down the biopsy channel of the endoscope to highlight the areae pattern, although there is a report that they have been seen on endoscopy and on endoscopy immediately after a barium meal (Glanville, 1975).

Received for publication 8 April 1977

\section{Anatomy}

The anatomist's concept of the areae gastricae is well illustrated in many textbooks of histology (Bloom and Fawcett, 1962; Elias and Pauly, 1966); basically, the gastric mucosa viewed en face looks like an irregularly ploughed field and the areas between the furrows contain a multitude of holes (Fig. 2). In section therefore the mucosa is 'perforated' by the gastric pits into which the gastric glands empty; the pits are lined principally by mucus secreting cells. The mucosa undulates in a fairly regular manner giving a cobblestone effect-the bottom of each groove commonly being bounded by a relatively large gastric pit. This undulation of the gastric mucosa is a fundamental intrinsic feature of the anatomy and is not dependent on the state of contraction of the muscularis mucosae and by definition is unaltered by the degree of stretching or contraction of the stomach wall (Fig. 3).

The first point to establish is whether the groove pattern of the anatomist formed by the undulating gastric mucosa 'perforated' by the gastric pits corresponds with the barium groove pattern of the radiologist.

\section{Correlation of anatomy and radiology}

To ascertain this correlation a portion of the antrum of a human stomach was taken from a surgically resected specimen and coated with barium; this was done by taking the fixed specimen and gently running barium on to it from a syringe and pouring the excess 


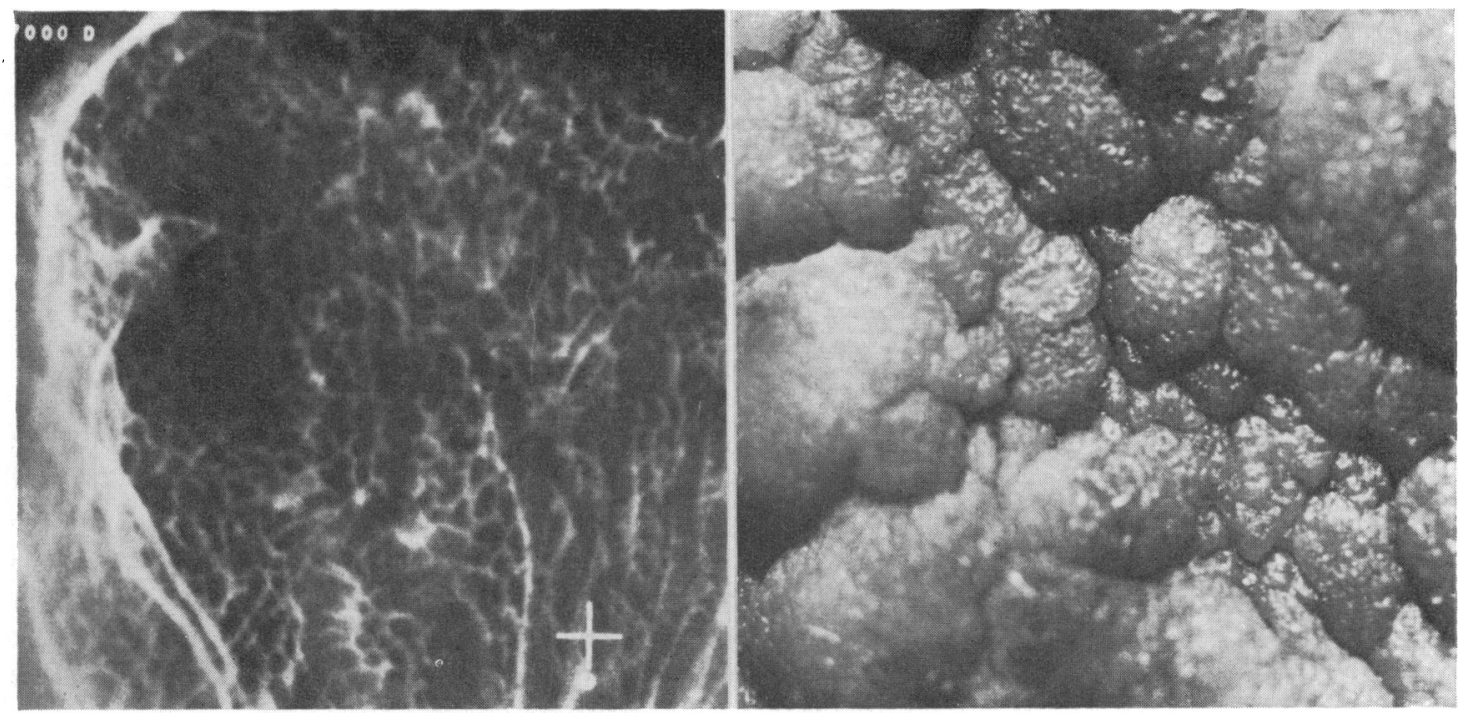

(a)

(b)

Fig. 1 (a) Spot film of the fundus of the stomach taken at a routine double contrast barium meal, showing the mosaic areae gastricae pattern. (b) Human gastric mucosa photographed en face at $\times 10$ (original) magnification showing the mosaic groove pattern.

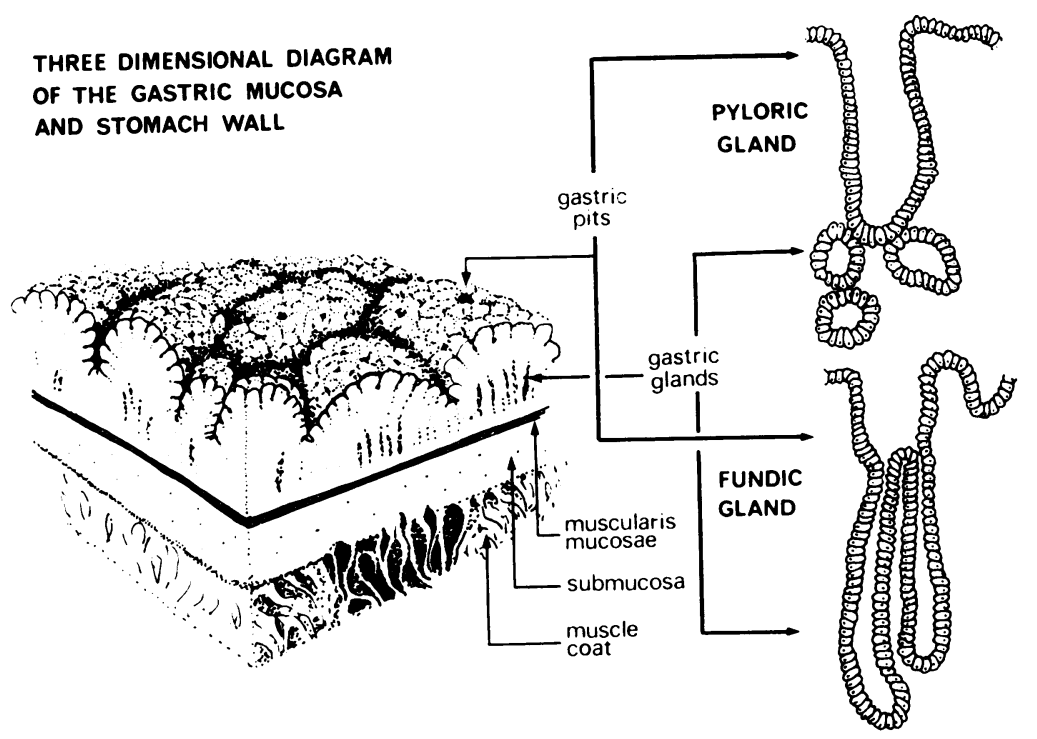

Fig. 2 Three-dimensional diagrammatic representation of the gastric mucosa with a representative antral and fundic type gland showing the difference in relative depth between the antral and fundic pits.

off (Kreel et al., 1974). The specimen was then photographed and radiographed and a fine mosaic barium groove pattern was demonstrated. A second specimen was taken from the anatomical body of the stomach and coated with barium; again a mosaic barium groove pattern was demonstrated, more coarse than in the case of the antrum. The specimen was photographed and radiographed and two small areas were identified in the specimen and films-one with four parallel barium grooves and one with a Y-shaped groove. These two portions were cut out of the specimens and serial sections cut at right angles to the grooves were prepared. It was clearly demonstrated that the barium grooves corresponded with anatomical grooves in the gastric mucosa (Fig. 4). 


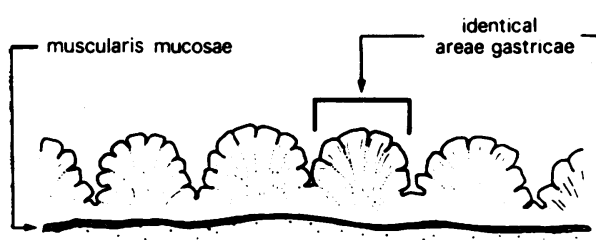

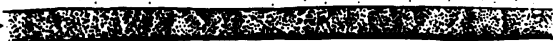

muscle coat
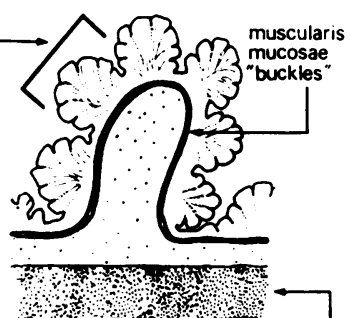

relatively thick muscle coat
Fig. 3 Diagrammatic representation of a microscopic section of the gastric wall showing the repetitive undulation of the mucosa typical of the antral mucosa and the lack of alteration in the areae gastricae whether the stomach is stretched or contracted.
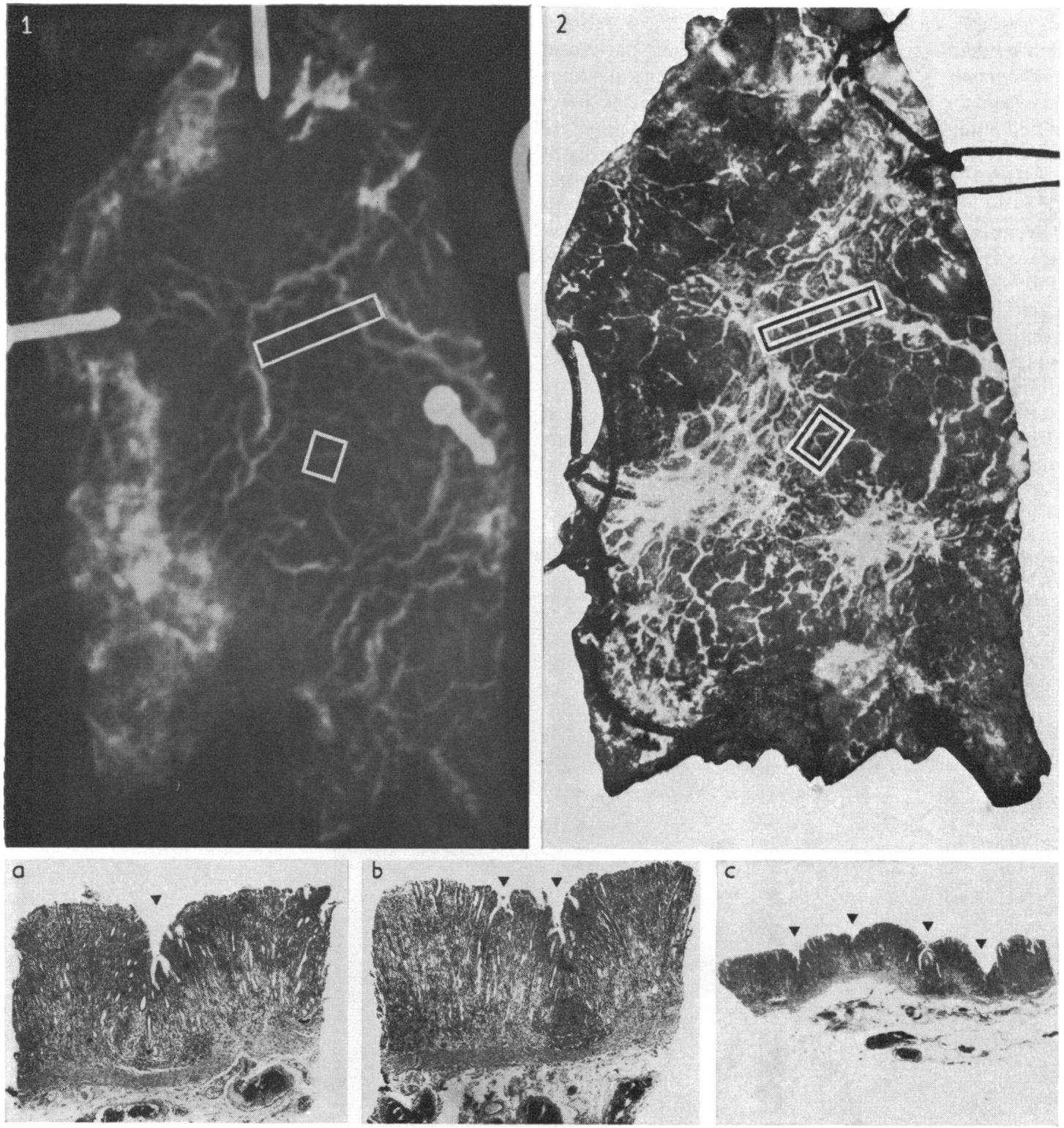

Fig. 4 1: Radiograph, 2: photograph ( $\times 3$ original magnification) of a portion of human stomach, body, coated with barium. The two portions removed for serial sections shown in the marked rectangle with four grooves and square with the Y-shaped groove: (a) and (b) are microscopic sections across the stem and arms of the Y-shaped groove, and (c) is a section of the upper rectangle with four grooves. In each case a groove is marked with a black arrow head. 
Because of the difficulty of obtaining specimens of the human stomach it was decided to use the pig stomach for the continued study of the areae gastricae anatomy. The pig stomach is a good model for the human, the main difference being the extension of the stratified squamous epithelium of the oesophagus down the lesser curve to abut on the antral type of mucosa. The areae gastricae pattern of the fresh isolated pig stomach is clearly visible to the naked eye and also when coated with barium as in the human specimen. After photography and radiography a clear mosaic areae gastricae pattern can be demonstrated (Fig. 5). The mosaic pattern in the antrum is relatively fine with a short distance between the grooves and, on occasion in the magnified image, there is an impression of a punctate pattern between the grooves themselves. A histological section shows the regular repetitive undulations of the mucosa giving the groove pattern with the multiple 'perforations' of the gastric pits; these are commonly large at the bottom of the grooves and shallower over the 'tufts' forming the areae gastricae. In the anatomical body of the stomach containing the fundic glands the grooves are much wider and further apart with a coarse mosaic quite different from the antral mucosa and a punctate pattern between the grooves is not clearly seen (Fig. 6). The anatomical fundus has a groove pattern intermediate in coarseness - that is, average distance between the grooves-between the antrum and body of the stomach. An 'intermediate' zone is noted between the antrum and body. This zone is quite narrow and shows the grooves becoming wider than in the anatomical antrum and merges into the coarse mosaic of the body 'acid-producing' mucosa. The antral pits in the pig and human are deeper than the fundic type and one might expect them to produce a more pronounced pattern between the grooves on these grounds. Histological sections taken through the site where the barium grooves are visible also show anatomical grooves, while the sections cut between the barium grooves in the body of the stomach show no anatomical grooves.

We have therefore demonstrated that the barium groove pattern corresponds with an anatomical groove pattern in the human and pig and that this pattern is distinctive in the anatomical antrum, body, and fundus (Fig. 7). This is easily and clearly reproduceable in double contrast barium meals performed in the isolated freshly fixed pig stomach in which the stratified squamous epithelium in the stomach can also be distinguished because of its characteristic 'wavy' barium groove pattern.

\section{Mucus layer}

It was noted that the longer the pig stomach was left after the surgical removal the more copious and tenacious was the layer of 'barrier' mucus over it.

The work to date on both the human and the pig

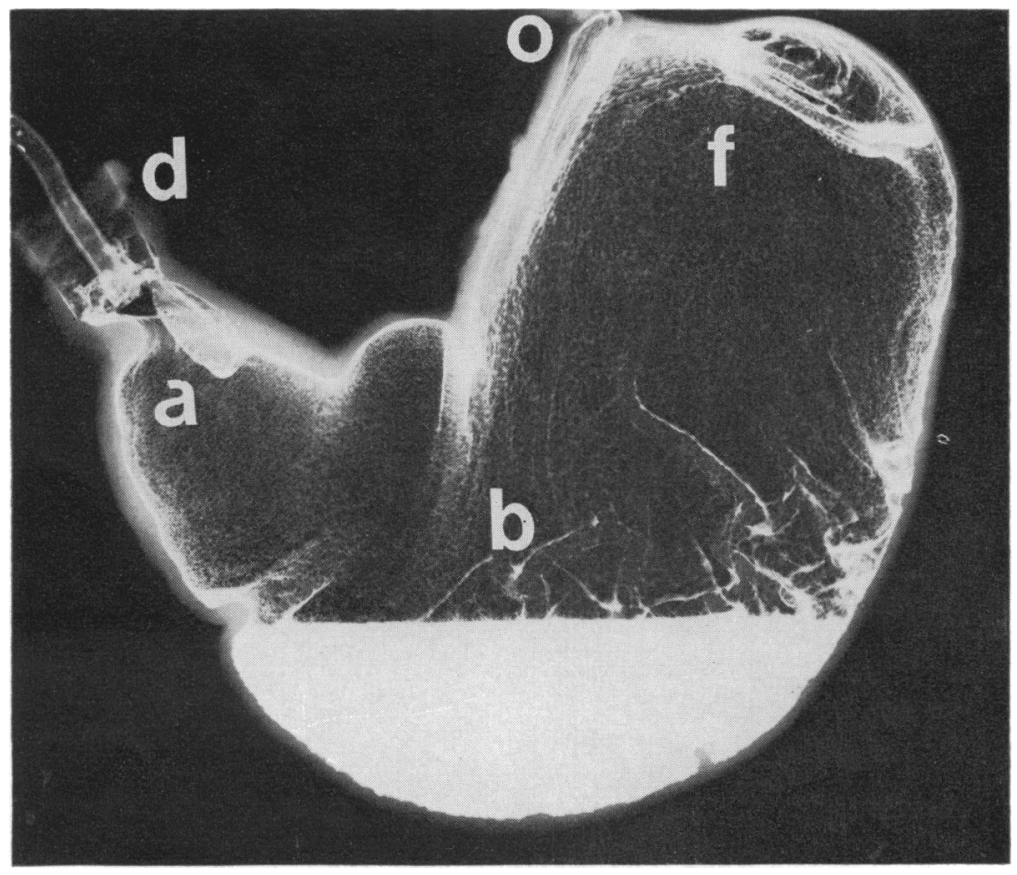

Fig. 5 Double contrast barium meal performed on the intact pig stomach (Kreel and Sandin, 1974b); d: duodenum with cork and tube inserted for barium and air insufflation; $a$ : antrum; $b$ : body; $f$ : fundus; $O$ : oesophagus tied off. 


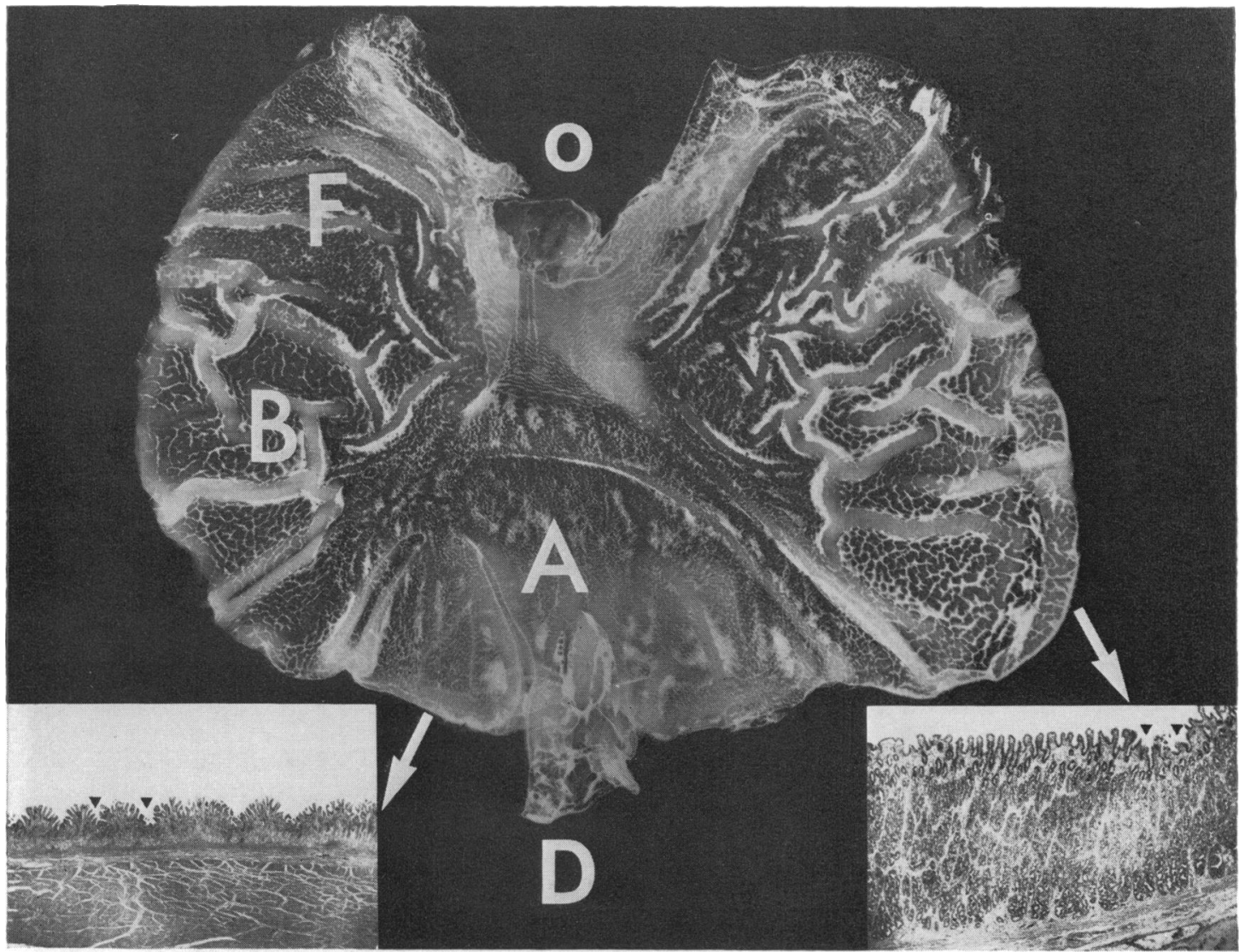

Fig. 6 Pig stomach shown in Fig. 5 divided along the greater curve and opened out and radiographed.

$O$ : oesophagus; $F$ : fundus; $B$ : body; $A$ : antrum; D: duodenum; wavy stratified squamous epithelium shown below the oesophagus. The insert on the left shows photomicrograph (low power) of typical antral mucosa with two adjacent grooves marked. The insert on the right shows photomicrograph of typical body mucosa with two grooves just joining marked.

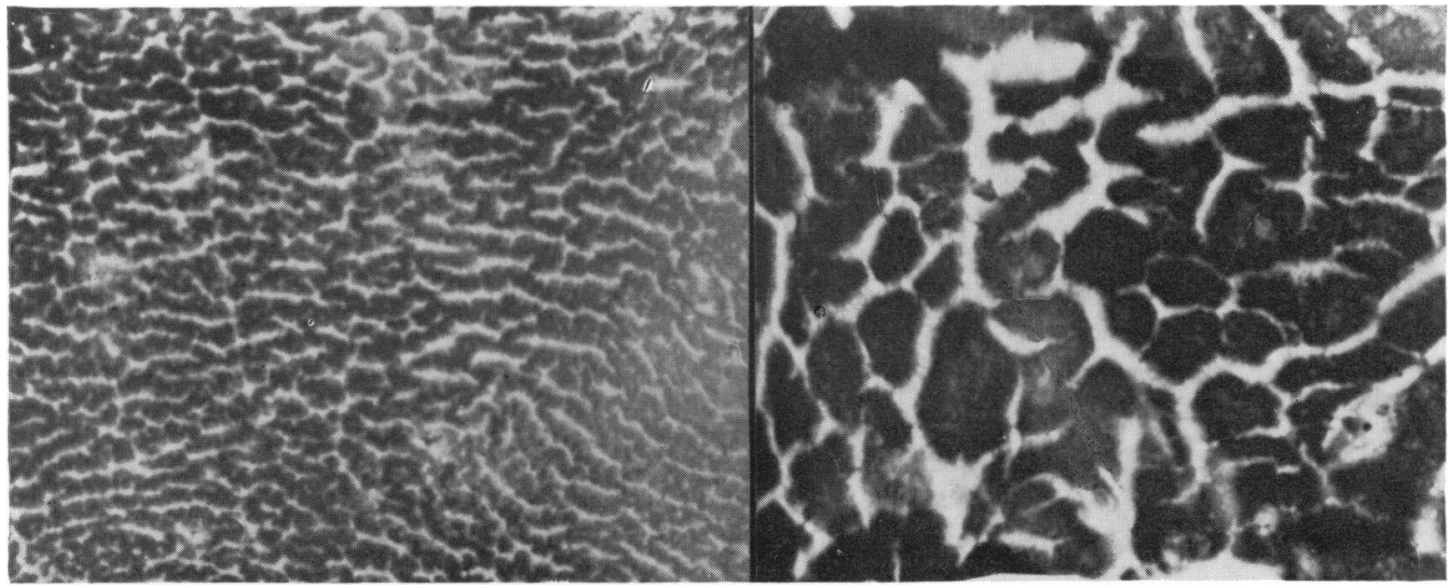

Fig. 7 Typical fine antral areae pattern in the pig $(\times 5)$ on the left with punctate pattern between and the coarse areae pattern of the 'acid-producing' body mucosa on the right. 

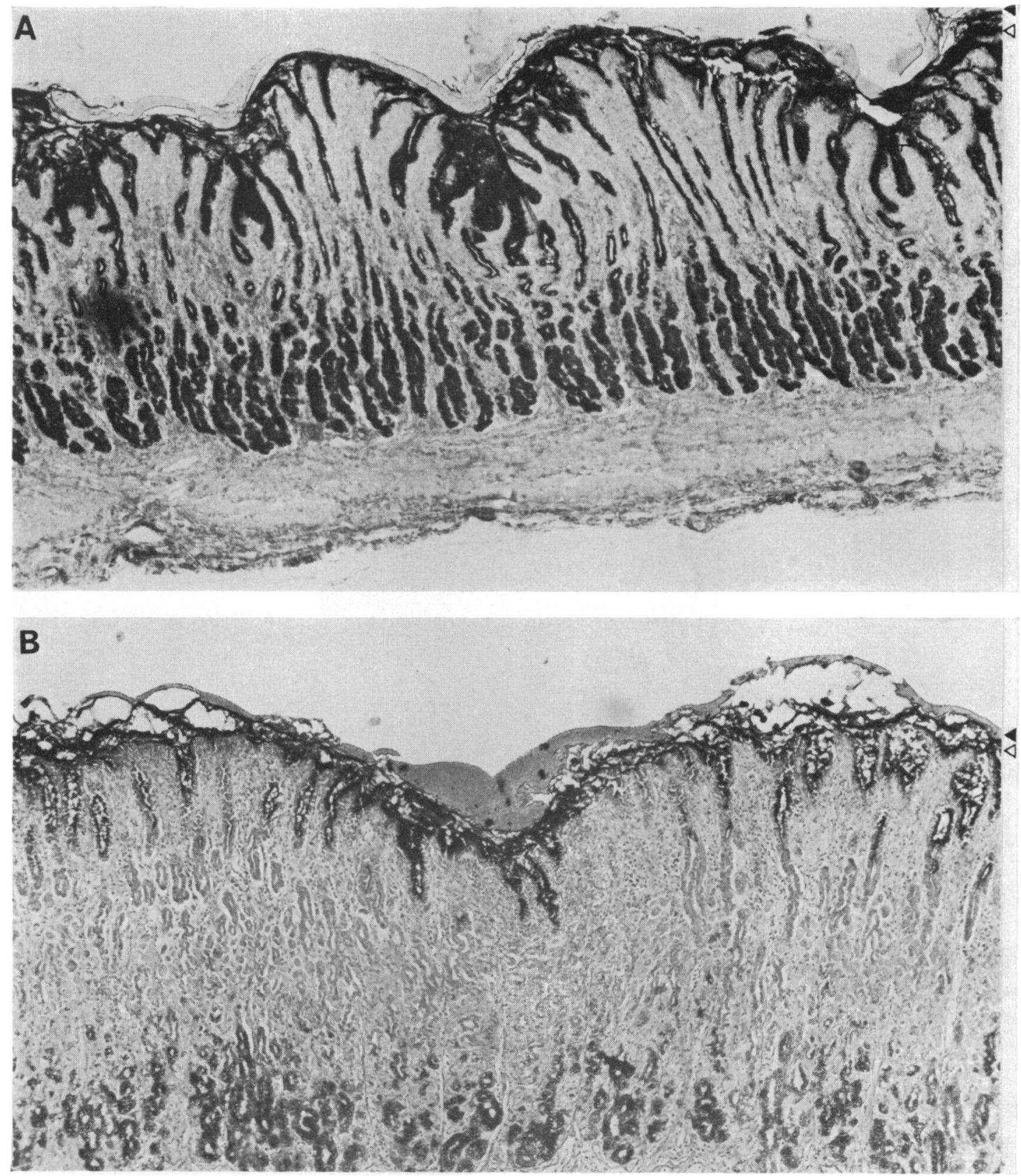

Fig. 8 (A) Pig antral mucosa (PAS stain) showing the barium on top of the mucus and the typical antral undulation. (B) Typical large body groove with barium 'pooling' in it. $\triangle$ Barium. $\triangle$ Mucus.

stomach had been done with specimens fixed with formol saline and washed 'clean'. The barium coated specimen may have had its coating of mucus and gastric secretions removed or significantly altered and in this respect it may not have represented the living state. To elucidate the barium groove pattern in a state as close to the living as possible pig specimens were used which were not 
washed in any way. The isolated pig stomach was taken and opened along the greater curve and gently spread out. Large particles of food matter were picked off the gastric mucosa and the specimen then coated with barium and radiographed. Grooves which were demonstrated were then removed and sectioned as before but on this occasion the specimens were stained for mucus with the PAS technique. In this way it was shown that the barium lies on top of the mucus layer and in no way percolates through it (Fig. 8). Where good coating is obtained the barium layer follows the relatively narrow mucus layer as it outlines the undulations of the gastric mucosa and gives an 'image' of the gastric mucosa in this way, the barium layer 'pooling' in the grooves and being thin over the 'tufts' which form the typical areae gastricae pattern in the stomach. When coating fails-that is, no groove pattern is shown-this is explained in some specimens by the thick mucus layer which 'irons out' the undulations of the gastric mucosa forming an entirely new 'relief map' which in its turn is outlined by the barium but bears no relation to underlying mucosal anatomy (Fig. 9). While varying thickness in the barrier mucus is important in the success of barium coating to show the areae gastricae so also is the thickness of the barium coat itself (Fig. 10).

\section{Areae gastricae on barium meal examination}

The radiologist's areae gastricae pattern reflects a true anatomical mucosal relief pattern which in the pig is distinctive in certain areas of the stomach. In 272 double contrast barium meals in humans the antral areae pattern was graded from 1-4 that is, average distance between grooves $1,2,3$, or $4 \mathrm{~mm}$ and non-visualisation graded as $\mathbf{0}$. It was found that $35 \%$ of the duodenal ulcer cases had a grade 4 pattern in the antrum and less than $3 \%$ of the duodenal ulcers occurred in the 'non-visualised' group (Fig. 11). This may reflect many factors such as grade 4 pattern in the antrum being associated with a high parietal cell mass but it also serves to draw our attention to the question of the gastric mucus layer which may be a decisive feature not only in the success or failure of the double contrast barium meal as an anatomical parameter of the situation but it may be that the double contrast meal technique is reflecting in some way the 'protective capability' of the mucus layer, the 'non-coater' having a low duodenal ulcer incidence, and the intense coater having a high incidence.

\section{Conclusion}

Radiological demonstration of the areae gastricae depends on a number of factors some of which are clearly evident. The type of barium is of central importance, some preparations giving good demonstration significantly more often than others (Kreel et al., 1974); the barium used in the present study lay. exclusively on top of the 'barrier' mucus layer

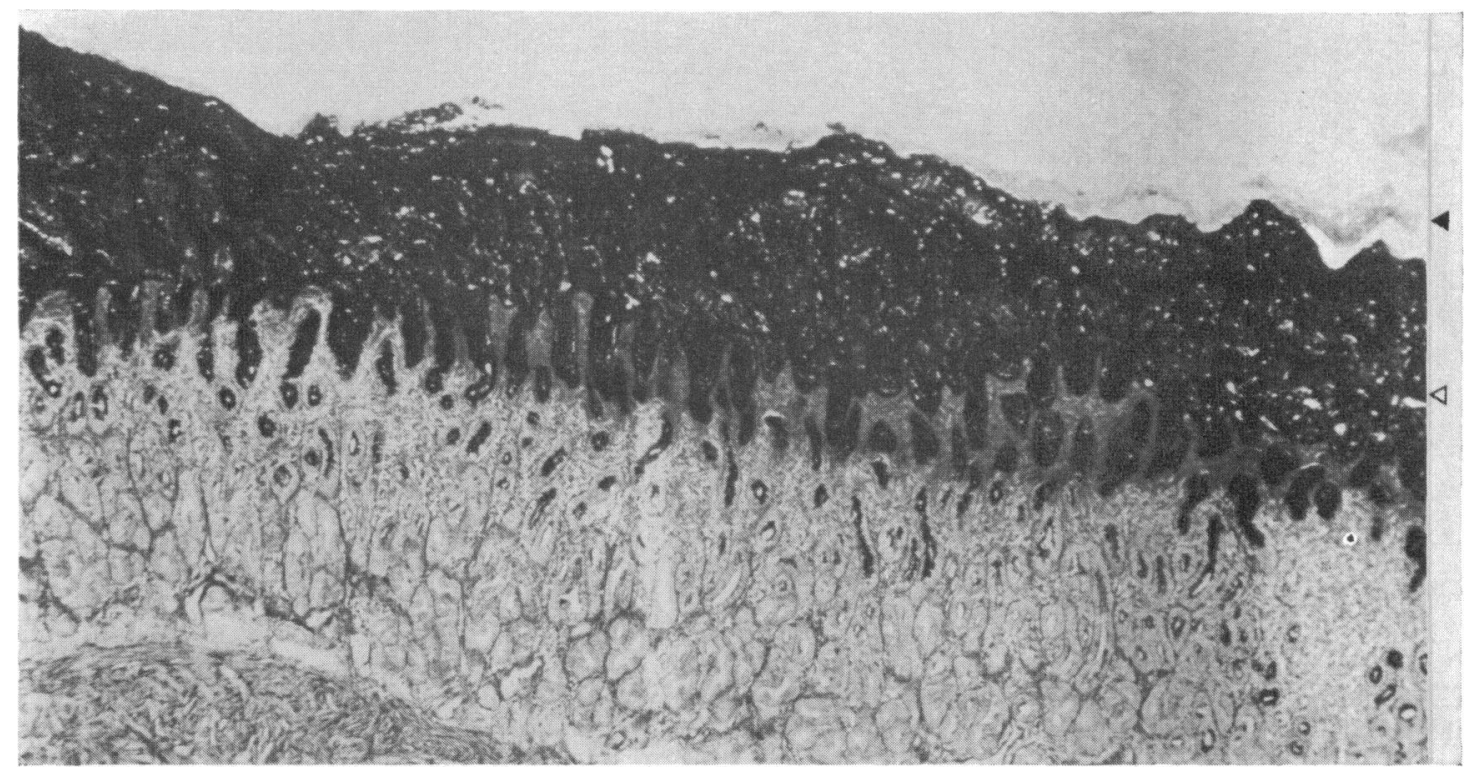

Fig. 9 Gastric mucosa (PAS stain) with excess mucus $(\triangle)$ layer (appears black) and thin coat of overlying barium ( $\mathbf{\Delta})$. 

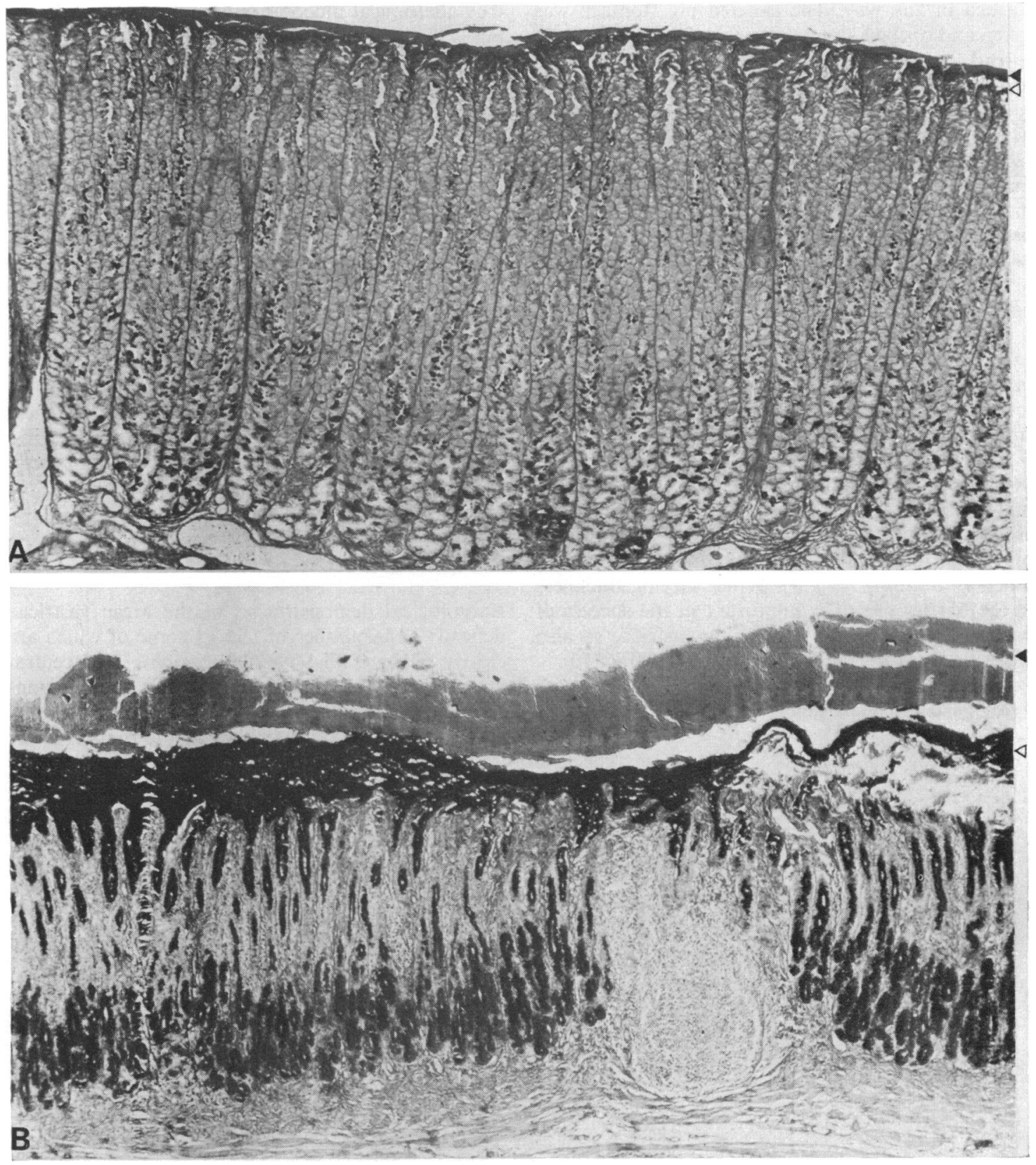

Fig. 10 (A) Section showing suitable thin layer of barium $(\Delta)$ and mucus $(\triangle)$ from the body of a pig stomach; the section does not cross any groove (PAS stain). (B) Section showing not only a thick mucus layer but also an excessively thick barium layer.

and in no way percolated through the mucus. The thickness of the mucus layer is of basic importance, as a thick layer will efface the undulations in the gastric mucosa which produce the areae pattern; the layer of barrier mucus should be of such a thickness that it allows the barium coating to reflect the underlying mucosal relief pattern. In studies of the relationship of barium to the gastric mucosa after coating the role played by mucus becomes evident only if specific stains for mucus are employed. From the 


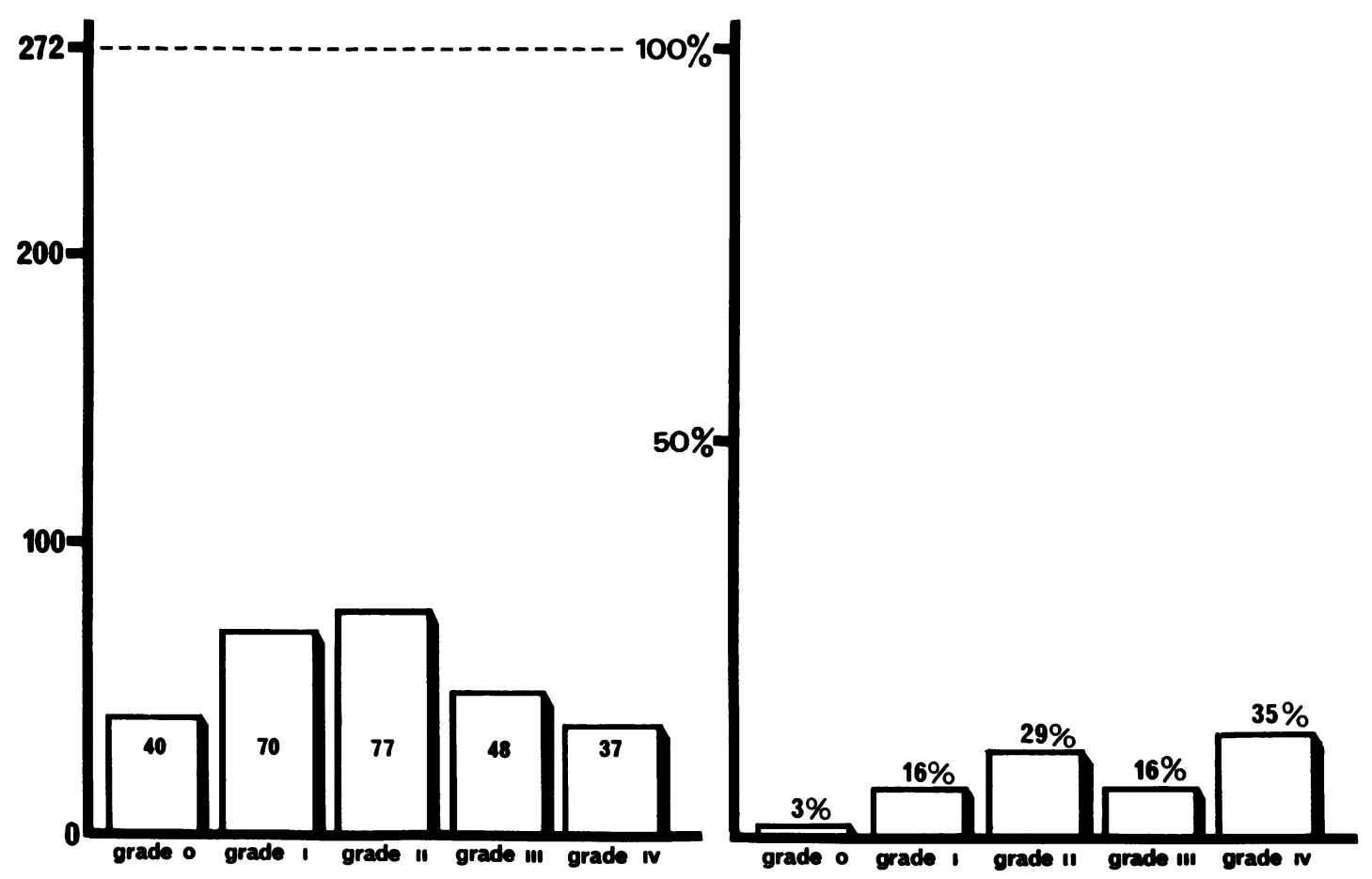

Fig. 11 Review of 272 double contrast barium meals in which the antral areae gastricae pattern has been graded ( 1 to $4 \mathrm{~mm}$ in diameter and grade 0 for 'non-coaters'). Distribution of grading shown in diagram on the left; on the rigth distribution of duodenal ulcer cases shown (in \%) according to the areae grading. Note high incidence in grade 4 and low in grade 0.

series of 272 double contrast meals reviewed it can be put forward that when a grade 4 areae gastricae pattern is visualised the likelihood of a duodenal ulcer being present is relatively high and when no areae pattern is visualised the incidence is low. The inference is that the non-coater has a thick barrier mucus layer and a low duodenal ulcer incidence, which is in keeping with experimental work on rats showing that drugs which promote ulcer healing such as carbenoxolone increase mucus secretion (Parke and Lindup, 1973) and ulcerogenic steroids experimentally reduce the amount of barrier mucus present (Corne et al., 1974). When a thick layer of mucus is present a characteristic radiological 'wavy' interference pattern is shown on barium coating as opposed to the areae pattern (Kreel, 1975). It seems clear that in clinical practice in the future histological examination of the gastric mucosa will need to be accompanied by an assessment of the mucus present.

Special thanks are due to Mrs. B. Sandin for radiography and Mr. C. Gilson of the Department of Medical Photography, Royal Free Hospital, and his staff for prints. The project was made possible by the supply of pig stomachs by Professor K. Hobbs, Professor of Surgery, Royal Free Hospital, and his colleagues during the liver transplantation research programme being undertaken at the Medical Research Council unit at Northwick Park Hospital. Also thanks are due to Dr. Ashley Price, Consultant Histopathologist, Northwick Park Hospital. The slides showing barium and mucus stained were possible due to the expertise of $\mathrm{Mr}$. Christopher Sowter, Chief Technician, Department of Physiology, Medical Research Council Unit, Northwick Park Hospital.

\section{References}

Bloom, W., and Fawcett, D. W. (1962). Textbook of Histology, 8th ed. Saunders: Philadelphia.

Corne, S. J., Morrissey, S. M., and Woods, R. J. (1974) $A$ method for the quantative estimation of gastric barrier mucus. Journal of Physiology (London), 242, 116-117.

Elias, H., and Pauly, J. E. (1966). Human Microanatomy, 3rd edition. Davis: Philadelphia.

Glanville, J. N., (1975). Areae gastricae and the endoscopist, in The Double Contrast Barium Meal. A Discussion Day in Leeds, 11 October 1975. pp 23-26. Sponsored by Concept Pharmaceuticals Ltd. 
Kreel, L. (1975). The surface pattern of the stomach. Proceedings of the Royal Society of Medicine, 68, 111-114.

Kreel, L., Herlinger, H., Sandin, B., and France, C. (1974). A technique for the in vitro testing of barium preparations. Radiography, 40, 51-55.
Kreel, L., and Sandin, B. (1974). Personal communication. Parke, D. V., and Lindup, W. E. (1973). Quantitative and qualitative aspects of the plasma protein binding of carbenoxolone, an ulcer healing drug. Annals of New York Academy of Sciences, 226, 200-213. 